\title{
LOS ESTABLECIMIENTOS DE AGUAS EN EL REALENGO ALICANTINO: UNA FORMA DE APLICAR EL CONTRATO ENFITEUTICO POR EL REAL PATRIMONIO A FINES DEL SIGLO XVIII
}

Por ARMANDO ALBEROLA ROMÁ

Universidad de Alicante

El presente trabajo pretende llamar la atención sobre ciertas escrituras notariales relativas a Rentas Reales conservadas en el Archivo Histórico Provincial de Alicante(t). En ellas se recogen todas las ventas, transmisiones, establecimientos diversos, deudas u otros asuntos convenidos entre el Real Patrimonio y sus enfiteutas alicantinos. De todos ellos haremos especial hincapié en un género de establecimientos poco reseñado normalmente, como es el de aguas.

La ciudad de Alicante, junto con los núcleos urbanos integrados en su jurisdicción, constituía uno de los dominios de realengo existentes en el antiguo Reino de Valencia. Al rey, pues, pertenecian por derecho de conquista todas las tierras baldias asi como el derecho a establecer enfitéuticamente casas, hornos, molinos, aguas, etc., obteniendo por ello unas rentas anuales en metálico(2).

En el establecimiento enfitéutico, el censatario o enfiteuta reconocía como dueño directo de la cosa censida al rey, y se obligaba al pago de un canon anual en metálico así como a respetar los derechos inherentes a la enfiteusis, tales como el pago del luismo o lluisme en las ventas, y la 
fadiga o derecho de preferencia para adquirir cualquiera de los dos dominios. El dueño directo, en este caso el rey, también poseía la facultad de exigir el cabreve o reconocimiento, cada diez años, del dominio que disfrutaba el enfiteuta.

Hasta la abolición de los Fueros valencianos, la administración del Real Patrimonio corría a cargo del Bat/e General, auxiliado por la Junta Patrimonial compuesta por el propio Batle, el Virrey, Mestre Racional, Asesor de la Bailía, Abogado Patrimonial, Receptor de la Bailia y Procurador Patrimonial. Para el mejor funcionamiento del sistema de cabrevación existian diferentes Ordenanzas promulgadas en 1527(3) y 1660(4); las cuales, además de regular la frecuencia con que habian de producirse los cabreves e intentar poner coto a cierta dejación producida en el control del Real Patrimonio por parte de sus funcionarios, dejaban traslucir un deseo por parte real de evitar mermas en los bienes recayentes bajo su patrimonio. Aunque, de todos modos, era patente que desde los mismos tiempos de la conquista los propios reyes habian ido enajenando sucesivamente aquéllos con la consiguiente mengua de los recursos que debía ingresar la Real Hacienda por este concepto(5).

La pérdida de la foralidad valenciana junto con la centralización administrativa, consecuencias ambas de la contienda sucesoria, vinieron a poner de manifiesto las cuantiosas enajenaciones producidas en los bienes patrimoniales que la Corona poseia en Valencia. La decadencia, según Branchat, habría que remontarla a los tiempos de la expulsión morisca, momento en que el Real Patrimonio, además de perder cierto número de vasallos, hubo de compensar a la nobleza valenciana afectada por la medida(6). Canga Argüelles añade también como motivos de desmembración patrimonial la guerra de las Germanias y "los ardides de los detentadores de las alhajas siempre que se trató de devolverlas a la coronaw(7). Además cabe añadir que tras la Guerra de Sucesión se produjo un gran confusionismo al ser abolidos el Tribunal del Batle y la Junta Patrimonial, organismos encargados de supervisar los asuntos patrimoniales, a la vez que se constataba que muchos derechos del Real Patrimonio eran enajenados o donados a particulares, sobre todo a miembros de la nobleza(8).

Los juristas valencianos de los siglos XVI y XVII cuando se refieren al Real Patrimonio inciden, básicamente, en la estructura organizativa del mismo soslayando su base económica; la cual, como ya se ha indicado, había sufrido una considerable dispersión motivada por las excesivas enajenaciones de que habian sido objeto los bienes pertenencientes a aquél. Es a partir de la segunda mitad del siglo XVIII cuando el interés de los tratadistas se ocupa, precisamente, de los aspectos económicos del Real Patrimonio en un claro intento de revisar y reincorporar los bienes enajenados en épocas pasadas(9). 
El año 1760 marca un giro clave en la politica a seguir respecto de la recuperación patrimonial tras el nombramiento de don Vicente Branchat como Asesor Patrimonial. Este, desde su importante puesto, iniciaria una acción tendente a incorporar nuevos bienes y revisar las enajenaciones efectuadas desde años atrás con el propósito de conseguir su devolución. Con Branchat se inicia, pues, la dificil tarea de intentar recuperar la Hacienda Real y revisar los derechos patrimoniales, obra que continuaría Canga Argüelles en la siguiente centuria.

Una de las principales facultades del Real Patrimonio residia en poder establecer tierras, casas, hornos, molinos, aguas y minas dentro de los ámbitos realengos y, a tal efecto, la Instrucción de 1783, recogida por Branchat(10) y promulgada con el deseo de aclarar el modo de llevarse a cabo los diversos expedientes de establecimiento, cabria incluirla dentro de esa política de recuperación patrimonial ya indicada.

\section{Los establecimientos de aguas}

Entre el amplio abanico de posibilidades ofrecido por los protocolos notariales de rentas reales, nuestro estudio va a centrarse en un único aspecto: los establecimientos de aguas; de los cuales existen ciertamente, pocas referencias debido a que han primado sobremanera las alusiones a roturaciones de tierras o establecimientos de casas y molinos, cuya concesión era mucho más generalizada.

El establecimiento y enajenación de las aguas públicas pertenecía en exclusiva al rey, considerándose como asunto de interés estatal la utiliza. ción del agua para irrigar las tierras o mover las ruedas de los molinos. Se podia solicitar el establecimiento de tres tipos diferentes de aguas, a los cuales los interesados debian hacer expresa referencia al elevar su petición:

a) Aguas sobrantes: eran aquellas que se perdian de forma irremediable una vez regados los campos o debido a su circulación incontrolada por pequeños torrentes y barrancos.

b) Aguas captadas de los ríos mediante ingenios hidráulicos 0 simples canalizaciones, y destinadas, fundamentalmente, al riego y fertilización de tierras.

c) Aguas subterráneas: eran las que ofrecian una mayor dificultad a priori para ser establecidas, puesto que para su localización y aprovechamiento se hacía preciso perforar el subsuelo.

En cualquiera de los tres casos, el mecanismo burocrático de establecimiento de aguas era similar, debiendo remitir los solicitantes sendos informes a los administradores o justicias de sus respectivas localidades en los que expusieran sus demandas, iniciándose a partir de esta premisa las 
diligencias que, según la complejidad del asunto, podían durar pocos días o algunos meses, e incluso algún año.

Quizá los casos que ofrecian mayores complicaciones eran los relativos a la extracción de aguas de los rios y a la localización y aprovechamiento de corrientes subterráneas. Respecto del primero se partía del principio referido a la posible privación del agua a antiguos riegos que tuvieran ya derechos adquiridos y un sistema de distribución acorde con ellos. Por ello se precisaba de los informes del Justicia en cuyo pueblo se fuera a realizar la toma de aguas así como las alegaciones de los ayuntamientos que aprovecharan las aguas del río. En ambos casos se tenian muy en cuenta los informes emitidos por los síndicos regantes de los diferentes municipios. Posteriormente el Justicia o Administrador de la localidad en cuyo término se solicitaba el desvío de una parte del caudal del río había de emitir nuevo informe en el que constara el grado de dificultad del proyecto y si se haría precisa la construcción de una presa asi como la indicación del lugar apropiado para la misma, con el fin de evitar posibles daños tanto en el momento de la obra, como en el futuro.

Cuando se trataba de aguas subterráneas, el trámite era algo más complejo ya que el Justicia, al recibir la solicitud de establecimiento, había de tener en cuenta si el terreno en el que se pretendía perforar era de realengo, propiedad particular del solicitante o de un tercero. Caso de que fuera de un tercero ajeno al asunto que no necesitara de esas aguas subterráneas, no había objeción alguna para que se iniciaran las diligencias acostumbradas. Ahora bien, si se oponía, el trámite quedaba de inmediato paralizado.

En los dos primeros casos, sin embargo, sólo habia que examinar si la conducción de aguas revestía dificultades y si había que hacerla pasar por tierras cultivadas. De producirse este hecho, se estudiaban los posibles perjuicios y la conducción se autorizaba de acuerdo con el valor y la superficie de las tierras que se hubieran de utilizar en la misma.

Respecto de las solicitudes de establecimientos de aguas sobrantes - uno de los casos más generalizados-era necesario como primera medida el nombramiento de peritos o síndicos de regantes que declararan la existencia real de esas aguas. Del mismo modo, debian hacer constar en sus informes el volumen de aguas sobrantes, si se perdian tras regar algunas tierras y si podían ser utilizadas sin causar molestia alguna a terceras personas. Un apartado final precisaba, en su caso, las obras que era necesario llevar a cabo.

Si el informe de los peritos resultaba positivo y favorable al establecimiento de las aguas solicitado se indicaba en el mismo el lugar más apropiado para construir una presa que permitiera el rebalso de las aguas, y las acequias que, saliendo de ellas, facilitaran la distribución de las mismas. 
Si las tierras por donde debian discurrir las aguas eran realengas no existía problema alguno, pero si pertenecian a particulares era preciso hacer constar el nombre de sus dueños, la calidad de las mismas y la estimación aproximada del perjuicio que la construcción de la acequia pudiera reportar, para lo cual se iniciaban unas diligencias paralelas. De todos modos, siempre cabía la posibilidad de que el solicitante tratara directamente del asunto con los propietarios con el fin de llegar a un acuerdo. Si éste se producía y no había objeciones por parte de aquéllos las diligencias reseñadas quedaban, logicamente, obviadas.

En cualquiera de los casos indicados, todos los expedientes pasaban a manos del Asesor Patrimonial una vez evacuado el informe de los Justicias, Abogado Patrimonial y Contador Principal. El Asesor, una vez examinados todos los escritos indicaba las posibles objeciones legales, si creia conveniente iniciar nuevas diligencias o la incorporación de cláusulas que evitaran dicusiones posteriores o, simplemente, se conformaba con el parecer de sus predecesores en el informe estimándolo correcto y recomendando su aprobación.

En el orden, llamémosle, operativo el Asesor hacía constar en su informe los medios que habian de ponerse en práctica para no causar molestias a los regantes. Igualmente señalaba si el solicitante debia hacer frente a los gastos derivados de la construcción de caños, partidores u otras obras de toma de aguas, así como el modelo que debían seguir las acequias de conducción, remitiendo en todos los casos al informe de los expertos. En última instancia, y si se hubieran producido negativas de los propietarios por cuyas tierras debian discurrir las acequias, decidía lo más conveniente de acuerdo con la ley. Los cánones que se hacían efectivos por los enfiteutas tenian una periodicidad anual y no contemplaban cantidades fijas, sino que se estipulaban "con arreglo a la costumbrew(11).

\section{El caso alicantino a tines deI XVIII}

Alicante y su término ofrecen unas peculiaridades climáticas y físicas que deben ser tenidas en cuenta en cualquier trabajo referido a problemas agrosociales durante el Antiguo Régimen. El clima es el típico mediterráneo, y la carencia de lluvias-excepción hecha de las torrenciales producidas en otoño y primavera-hacía que antaño las disponibilidades hídricas sufrieran una considerable merma durante el periodo estival, con el consiguiente perjuicio para ciertas cosechas.

Al N.E. del perímetro urbano se extendia la zona conocida como "Huerta de Alicante", calificativo que no debe inducir a errores por comparación con otras huertas próximas como la valenciana. En el caso alicantino la denominación más precisa seria la de "secano mejorado". La huerta disponía de un único caudal de agua-el del rio Montnegre-y para asegurar un riego mínimo al año el común de la ciudad construyó, a finales del 
siglo XVI, un pantano en el vecino término de Tibi con el fin de retener las aguas del Montnegre y poder utilizarlas en épocas de escasez. Este hecho originó un complejo sistema de riego caracterizado por el control ejercido en el tiempo de disfrute del agua(12).

Las zonas del W. y S.W. de la ciudad estaban ocupadas por las partidas de secano en las que las posibilidades de riego eran mucho más limitadas: algunos pozos y norias, balsas para recoger agua de lluvia, aprovechamiento de la que descendia en ocasiones por las laderas de los montes $y$, en algunos casos, utilización de pequeños manantiales cuyos caudales no eran ciertamente notables(13). Por ello, los cultivos dominantes en este ámbito eran, sobre todo, de arbolado, vid de secano, barrilla y cebada.

En la segunda mitad del siglo XVIII, la ciudad de Alicante vivió una gran ansia roturadora, un deseo de ampliar las tierras cultivadas debido a la existencia de posibilidades económicas y a las condiciones favorables que los contratos enfitéuticos ofrecian a los labradores o a los simples hombres de negocios ávidos de invertir en bienes raices. En la huerta ya no habia posibilidad de nuevas roturaciones debido a la excesiva fragmentación de la propiedad y, por ello, los interesados en conseguir nuevas tierras fijaron su atención en las extensiones yermas próximas a los secanos ya en cultivo.

Las demandas de establecimientos de tierras baldias recibidas en la Bailia de Alicante en las dos últimas décadas del siglo XVIII excedieron, con mucho, las posibilidades de concesión ya que, en numerosos casos, el establecimiento afectaba gravemente a zonas útiles como pastizal o productoras de esparto y leña. A este respecto resulta suficientemente gráfica la respuesta dada por el ayuntamiento de la ciudad a una de las muchas peticiones que fueron denegadas

"...en consideración a que por los muchos establecimientos que hasta ahora se han concedido ha llegado el caso de quedar muy corta porción de tierras para el pasto de ganados y producción de leñas y atochas, cuya escasez se experimenta en notorio perjuicio del público y aún del Real Servicio, conceptúa este llte. Ayt. ${ }^{\circ}$ deve negarse.... (14).

En base a esta politica seguida por el Real Patrimonio, en la que los ayuntamientos jugaban un papel fundamental puesto que eran los que informaban a favor o en contra de las demandas, el concejo alicantino denegó entre 1781 y 1804 un total de 26 solicitudes de entre las 71 que le fueron presentadas para emitir informe. Estas decisiones traducidas en unidades de superficie significan que de los 876 '5 jornales de tierra- 1 jornal $=$ 0‘4804 Ha.- que podian haberse puesto en producción al ceder su dominio útil al Real Patrimonio, tan sólo alcanzaron el permiso preceptivo 538‘5 
jornales(15). No obstante, dentro de este contexto de solicitud-denegación de establecimientos de tierras baldías en enfiteusis se observan dos claros períodos en esos últimos veinte años del siglo XVIII. Un primer período seria el comprendido entre 1781 y 1790 en el que se producen 37 solicitudes que comportan 577 jornales de tierra. De éstos no consiguieron autorización para ser establecidos 170 jornales tan sólo, lo que supone un porcentaje positivo de más del $70 \%$.

El segundo período, entre 1791 y 1804 , ofrece características diferentes. Es un hecho constatado que a partir de 1790 se endurece la postura municipal por los argumentos anteriormente expuestos-vid. nota 14-. Por ello, pese a que no existe un retraimiento en cuanto al número de solicitudes - 34-con respecto al anterior periodo, si se observa una considerable reducción en lo que a superficie se refiere. De los 299 '5 jornales solicitados tan sólo obtienen autorización 131 , 5 , poco más del $40 \%$ del total del periodo, con lo que la posibilidad de panificar tierras del Real Patrimonio mediante enfiteusis queda prácticamente reducida a nada. El cuadro que sigue clarifica en gran medida lo detallado hasta aqui.

\section{ESTABLECIMIENTOS DE TIERRA CONCEDIDOS POR EL REAL PATRIMONIO EN ALICANTE (1781-1804)}

\begin{tabular}{|c|c|c|c|c|}
\hline Año & Solicitudes & $\begin{array}{l}\text { Superficie } \\
\text { (Jornales) }\end{array}$ & Denegaciones & $\begin{array}{l}\text { Superficie } \\
\text { (Jornales) }\end{array}$ \\
\hline 1781 & 5 & 49 & - & - \\
\hline 1782 & 3 & $43^{\prime} 5$ & - & - \\
\hline 1783 & 4 & 56 & 1 & 16 \\
\hline 1784 & 5 & 54 & 3 & 29 \\
\hline 1785 & 2 & 14 & 1 & 10 \\
\hline 1786 & 6 & $80 ` 5$ & - & - \\
\hline 1787 & 5 & 115 & 2 & 95 \\
\hline 1788 & 4 & 151 & 2 & 20 \\
\hline 1789 & 3 & 14 & - & - \\
\hline 1790 & - & - & - & - \\
\hline 1791 & 6 & $32 \times 5$ & - & - \\
\hline 1792 & - & - & - & - \\
\hline 1793 & 1 & 1 & - & - \\
\hline 1794 & 1 & 20 & - & - \\
\hline 1795 & 1 & 18 & 1 & 18 \\
\hline 1796 & 2 & 8 & 2 & 8 \\
\hline 1797 & 2 & 30 & 1 & 10 \\
\hline 1798 & 2 & 20 & 1 & 10 \\
\hline 1799 & 6 & 30 & 5 & 24 \\
\hline 1800 & 4 & 54 & 3 & 51 \\
\hline 1801 & 1 & 18 & 1 & 18 \\
\hline 1802 & - & - & - & - \\
\hline 1803 & 4 & $41^{‘} 5$ & 1 & 16 \\
\hline \multirow[t]{2}{*}{1804} & 4 & $26^{\circ} 5$ & 2 & 13 \\
\hline & 71 & $876^{4} 5$ & 26 & 338 \\
\hline
\end{tabular}

Fuentes: A. M. A. Cartas Escritas, Armario 12, Libros 64 a 69.

A. H. P. A. Establecimientos posteriores al cabreve, $\mathrm{HB} / 800$.

Elaboración propia. 
En este punto y cuando los informes de las autoridades alicantinas comenzaron a denegar sistemáticamente, a partir de 1791, nuevos permisos para roturar, es lógico que se intentaran propiciar formulas que, por otros cauces, pudieran hacer posible la puesta en producción de nuevas tierras, mejorar las ya existentes o, tan sólo, obtener ciertas ventajas económicas en un momento en que la coyuntura general se presentaba favorable(16). Este podría ser el caso de los establecimientos de aguas en el realengo alicantino, los cuales entrarían de lleno en esa mecánica inversionista ya apuntada y servirían a sus solicitantes para conseguir irrigar sus secanos o, como más adelante podremos observar, utilizar un establecimiento de aguas para un fin totalmente distinto del aducido en la solicitud.

A partir del año 1790 tienen entrada en la Bailia de Alicante sucesivos Memoriales en los que se solicitaba el establecimiento enfitéutico de determinadas aguas conceptuadas como «sobrantes". Entre ellos cabe destacar el firmado por D. Juan Bautista Caturla, D. Nicolás Pro, D. Gaspar Welther y $D$. Lorenzo Darreglade, individuos de cierto rango social y consideración dentro de la ciudad, pretendiendo la concesión de cinco fuentes que, al fluir en invierno por el denominado Barranco de las Ovejas, únicamente eran aprovechadas por don Julián Colomina, perdiéndose el resto en el mar'17).

Las solicitudes indicaban en su Memorial que estas aguas sobrantes, así como las de avenida producidas en época de lluvias, podian ser utilizadas para regar tierras de su propiedad construyendo el correspondiente azud o presa, y por ello solicitaban que le fueran establecidos dichos caudales de forma mancomunada.

De inmediato fueron presentados recursos de diferentes personas que aducian un derecho preferente al establecimiento de las mencionadas aguas. Tras los informes del Abogado Patrimonial y del Contador, el Asesor remitio al Intendente General del Reino un memorial en el que, curiosamente, se reconocian los derechos de alguna de las personas que habían presentado recursos pero, a la postre, se daba el visto favorable para la concesión de la licencia de establecimiento. En efecto, a juicio del Asesor, don Julián Colomina y los herederos de Pablo Mallol, que habian interpuesto recurso a la solicitud, poseian «indisputable derecho en el día a las expresadas aguas" en virtud, respectivamente, de escritura fechada en 1729 y de una sentencia de la Real Audiencia que confirmaba el uso exclusivo de las dos primeras fuentes del Barranco(18). No estaba en el ánimo del Asesor discutir, pues, la propiedad del nacimiento de las aguas ni el derecho de uso preferente para el riego ya que aquéllas, al brotar dentro de una propiedad privada-las tierras de Colomina y Mallol-no se conceptuaban como realengas en ese punto. Sin embargo el Asesor Patrimonial entendía que también existian aguas sobrantes que, según el informe de 
los peritos a cargo del asunto, en clertas ocasiones se perdian pero en otras quizá no llegaban a bastar para el riego de las tierras pertenecientes a los dueños de las fuentes. Ante la duda planteada sobre a quién correspondia conceder el establecimiento del citado sobrante de aguas, el Asesor consideró que "conforme al bien del Estado" debía ser establecido preferentemente a los señores Caturla, Pro, Welther y Darreglade, una vez fuera utilizada por los herederos de Pablo Mallol y por don Julián Colomina. Ambos debian indicar la superficie de tierras que en el momento de elaborar el informe estaba en disposición de recibir riego de las ya citadas fuentes.

Tras acreditar Colomina que en su heredad del Barranco de las Ovejas regaba 142 tahúllas de tierra -1 tahúlla $=0 ` 12 \mathrm{Ha} .-$, y ser imposible para los herederos de Mallol justificar las tierras que poseían, una Real Resolución acordaba conceder en noviembre de 1788 el establecimiento de las aguas sobrantes a los cuatro solicitantes con expresa indicación de que tan sólo se les establecía el dominio útil de las mismas, puesto que el directo pertenecía al rey. La pensión anual que debian satisfacer al Real Patrimonio en el día de San Miguel ascendía a 7 libras por cabeza, debiendo además los solicitantes someterse al resto de los derechos propios de la enfiteusis. Como obligación especial se hacía constar la de fabricar un acueducto, con el fin de conducir las aguas y evitar su pérdida, así como una presa en el lugar indicado por los expertos. El tiempo límite concedido para la realización de las obras era de año y medio, y si en ese término no se hubieran llavado a cabo se procedería al comiso de las aguas sobrantes establecidas.

Uno de los solicitantes, D. Gaspar Welther, considero excesivo el canon impuesto y desistió de su pretensión. De inmediato, Vicente Matet, uno de los individuos que habia elevado recurso de derecho preferencial, pretendió subrogarse en lugar de Welther, cosa que, tras la correspondiente instancia, consiguió.

Tras el establecimiento de las aguas, los solicitantes desvelaron las superficies de tierra que se iban a beneficiar con el uso de aquéllas y que, como se observará, suponían cantidades nada desdeñables. Don Juan Bautista Caturla indicó que sus propiedades en la zona ascendian a 2.000 tahúllas, distribuidas en tres heredades y dos huertos con noria y balsa, ubicadas en las partidas del Llano del Espartal y del Bavel. Los herederos de don Nicolás Pro-fallecido durante la incoación del expediente-declararon poseer 136 tahúllas en la partida del Llano del Espartal. A estas superficies se unieron 311 tahúllas de don Lorenzo Darreglade en el Llano del Espartal y 760 tahúllas en la misma partida, propiedad de Vicente Matet. Como se ve, gracias a este establecimiento de aguas sobrantes, se pudieron irrigar 3.207 tahúllas de tierra secana que, de otro modo hubiera sido imposible lograr. Los máximos beneficiados, por 
supuesto, eran los propietarios pues con un desembolso anual de 7 libras, junto con los gastos que ocasionaran las obras de construcción, podrían disfrutar por tiempo indefinido gracias al contrato enfitéutico de unos caudales de riego que, aunque pudieran resultar intermitentes en función de la climatologia y las necesidades de los primeros regantes, resultaban básicos para transformar la economia agraria de sus posesiones. Del mismo modo, el Real Patrimonio al acrecentar en 21 libras los ingresos que anualmente percibia en la Bailia de Alicante justificaba su politica de recuperación de antiguos bienes y la incorporación de otros de nuevo cuño.

Dentro de este mismo contexto se incluirian pequeños establecimientos(19) y, con ciertas matizaciones, la solicitud de don Francisco Puigserver, comerciante al por mayor instalado en Alicante, relativa a la concesión en enfiteusis de dos manantiales nacidos en la partida de Agua Amarga y fluyentes por el barranco realengo del mismo nombre(20). Aducia, al igual que en el caso antes citado, que los caudales se perdian en el mar pero, convenientemente utilizados, podrian beneficiar a su hacienda situada inmediata al barranco. Proponía, además, la construcción de una presa y un artefacto para elevar las aguas a distintos niveles, evaluando las obras de los mismos en unas 2.000 libras. Como colofón de su memorial, redactado en julio de 1790, hacía hincapié en que dicho establecimiento de aguas no perjudicaría a nadie sino más bien al contrario, ya que el Real Patrimonio obtendria el pago de un canon anual y el común de las gentes se beneficiaria al poderse evitar, con sus obras, que las aguas quedaran detenidas, corrompiéndose y produciendo fiebres tercianas.

Los diferentes informes evacuados indicaron la conveniencia del citado establecimiento, el cual fue concedido en noviembre de 1790 en los términos conocidos de la enfiteusis y con una pensión anual de tan sólo una libra, puesto que se habia tenido en cuenta para fijar el canon el costo de las obras a realizar y que la estimación de las aguas hecha por los peritos ascendía únicamente a 350 libras. No obstante, como cláusula final, la Real Resolución pormenorizaba todas las obras que debian llevarse a cabo en el plazo de cinco años so pena de comiso'21).

Hasta aquí todo se desarrollaba dentro de los cauces habituales, pero al cabo de un año volvemos a encontrar al comerciante Puigserver solicitando un nuevo establecimiento sobre el ya anteriormente conseguido(22). En este caso señalaba en su memorial que las aguas sobrantes que le habían sido concedidas enfitéuticamente sólo podian regar una parte minima de su propiedad debido a que ésta estaba dispuesta a diferentes alturas, no llegando el riego a las partes más elevadas. Por ello solicitaba le fuera concedido permiso para construir un molino harinero que sería movido por las aguas anteriormente establecidas. El gasto de esta empresa sería de tan sólo 500 libras, evidentemente menos gravosos que el comportado por el complejo sistema de presa y conducciones planeado con anterioridad. 
La idea no era en absoluto novedosa puesto que ya en 1751 el ayuntamiento alicantino había considerado una similar propuesta elevada por Luis Galvany, vecino de la ciudad, para edificar un molino harinero en el barranco de Agua Amarga(23). Galvany consideraba, tras examinar el lugar y la frecuencia de las aguas, que la idea del molino beneficiaría a los labradores de la vecina partida de Bacarot y evitaría el embalse de las aguas y las subsiguientes tercianas. El cabildo acordo, sin mayores problemas, "condescender a la pretensión del referido en quanto fuese de parte de la ciudad, dejando salvas las regalías del Real Patrimonio...". De hecho, el establecimiento no debió llevarse a cabo, fue abandonado al cabo de cierto tiempo o sufrió el comiso puesto que no aparece ninguna referencia a él en el cabreve de la Bailia realizado en 1781.

El conocimiento de esta anterior situación debió influir para que $D$. Francisco Puigserver subrayara en su informe los aspectos más favorables de su proyecto. Si éste era llevado a buen término el Real Patrimonio saldría, cómo no, beneficiado; pero sobre todo resultaria positivo a los vecinos de la partida de Agua Amarga debido a la inexistencia de molinos en un radio de dos leguas. Los más próximos se ubicaban en la huerta alicantina, en el cauce del Montnegre, y cuando por falta de agua no funcionaban-cosa harto frecuente durante la epoca estival-los labradores debian desplazarse fuera del término para llevar a cabo sus moliendas, con lo que el precio de la harina experimentaba acusadas subidas. EI Abogado Patrimonial no observó dificultades y autorizó el establecimiento que, al cabo de dos años, mostraba bien a las claras los deseos de su solicitante, ciertamente distintos a los manifestados en la primera petición. Así pues, D. Francisco Puigserver obtuvo la correspondiente licencia para construir su molino harinero en los términos ya conocidos, con la obligación de tenerlo en funcionamiento en un plazo no superior a cuatro años, junto con el pago de una pensión anual el dia de San Miguel de 2 libras al Real Patrimonio por cada una de las muelas que contuviera en su maquinaria.

Pero la solicitud de establecimiento que ofrecía un proyecto más ambicioso vino de parte de D. Tomás Pavía y los hermanos Manuel e Ignacio Raggio, prósperos comerciantes residentes en la ciudad. Estos pretendian desecar 129 jornales de marjal, existentes en la partida de la Albufereta, con el fin de poderlos reducir a cultivo y, a la vez, acabar con uno de los principales focos de fiebres tercianas existentes en el término de la ciudad(24).

Era éste un viejo proyecto que las autoridades locales intentaban llevar a cabo, sin éxito, desde fines del siglo XVII. En el fondo del asunto subyacía un grave problema de salubridad: la laguna o estanque de la Albufereta, situado en el extremo sur de la Huerta de Alicante y al N. E. de la Sierra de San Julián o Serra Grossa, constituia un foco de fiebres 
tercianas que, invariablemente, hacían su aparición cuando los calores estivales apretaban. Cavanilles, siempre puntual en sus descripciones, indicaba que el problema se agudizaba al producirse la periódica limpieza del pantano que abastecía de agua a la huerta, puesto que con la llegada de las aguas "turbias e infectas" y su posterior consumo por los moradores cercanos a la laguna, las tercianas se generalizaban y expandian hacia el interior de la huerta alicantina(25). Las referencias al asunto son numerosas, y los Memoriales en los que se contienen las quejas de los vecinos de las zonas afectadas y colindantes se acumularon con frecuencia en las mesas de los rectores municipales(26).

Los intentos de desecación se sucedieron a lo largo de los siglos XVII y XVIII, y hubo momentos en los que las obras se habian arrendado, elaborado capítulos de construcción y planos, y aprontado los recursos necesarios. Pero todo ello en vano; hasta el punto de que el proyecto llegó a ser conceptuado como irrealizable. Por ello, cuando en septiembre de 1788 se presentó en la Bailía la solicitud de los individuos ya citados fue recibida con los pronunciamientos más favorables; indicándose que, de llevarse a cabo el proyecto, se obtendria un notable beneficio, tanto para los habitantes de las partidas más próximas a las aguas como para los ciudadanos alicantinos en general. Con arreglo a esta intención se autorizó, en primera instancia el establecimiento con la condición única de que los solicitantes dieran salida a las aguas que, una vez panificada la zona, pudieran remansarse.

El Abogado Patrimonial, tras recibir el informe favorable del municipio, no lo admitió porque don Tomás Pavia y los hermanos Raggio no presentaban en su memorial un plano con las acequias de desagüe ni indicaban el tiempo que les llevaría concluir la desecación y poner en producción las tierras. Por este motivo el proyecto estuvo paralizado durante un año, hasta que el buen criterio del Contador Principal dio un nuevo sesgo al asunto. El Contador juzgaba lógico que los solicitantes no quisieran comprometerse en plazos de tiempo fijos debido a la ignorancia de las dificultades que un terreno pantanoso pudiera deparar. Por ello consideraba aceptable el plazo de diez años que proponían en su escrito, apoyando su opinión en el hecho de que se trataba de un "establecimiento de clase extraordinarian y que sólo podría ser llevado a cabo por gentes adineradas como lo eran los peticionarios.

El criterio del Contador Principal prevalecio y los 129 jornales de tierras pantanosas de la Albufereta fueron establecidos enfitéuticamente con las condiciones habituales en este contrato, debiendo quedar desecada la zona y puesta en cultivo en un plazo de diez años. El canon anual que la Real Resolución señaló no fue excesivo; tan sólo 6 dineros por cahizada "por el conocido interés que ha de resultar a la utilidad y a la salud pública y crecidos gastos que les han de ocasionar el desagüe y cultivos». 
De hecho la desecación no se llevó a cabo-pese a que no hemos conseguido hallar constancia documental del comiso por el Real Patrimonio-pues hasta la década de los treinta del presente siglo no se produjo

saneamiento y bonificación de la laguna de la Albufereta(27).

En las diferentes solicitudes de establecimiento de aguas examinadas siempre se constataba que se quieren realizar por el bien común general y en beneficio del Real Patrimonio. A la vista de los ejemplos reseñados cabría plantearse cuáles eran los verdaderos intereses que movian a los peticionarios, los cuales sin apenas desembolsos iniciales y mediante compensaciones anuales al Real Patrimonio, a veces ridículas por su exigüidad y que rápidamente quedaban devaluadas, obtenian el uso de unos bienes-en este caso aguas-durante un tiempo indefinido que, en resumidas cuentas, les producian beneficios más interesantes de los indicados en las actas de solicitud de establecimiento.

Los intereses de los solicitantes eran, a todas luces, obvios. La mayoria de ellos pertenecía a clases acomodadas ciudadanas, tratándose sobre todo de caballeros y comerciantes. Todos disponían de los recursos necesarios para ampliar sus fortunas y haciendas, resultándoles, además, favorable la coyuntura económica del momento. El movimiento del puerto alicantino y el gran volumen de exportación vinatera eran propicios a las compañias comerciales asentadas en la ciudad y a los grandes cosecheros de vino de la huerta. Las facilidades económicas ofrecidas en el contrato enfitéutico invitaban a invertir, sin grandes problemas, en bienes realengos. Por otra parte, el frenazo dado a las roturaciones de tierras baldias a fines del XVIII debido a la gran demanda existente hizo que los que poseían tierras en secano ingeniaran los métodos más adecuados y menos onerosos para extraerles el máximo rendimiento y rentabilidad. En este caso, el disponer de corrientes de aguas sobrantes podía suponer cierta reconvención de las explotaciones aunque a escala limitada como es lógico. El deseo, por otro lado, del Real Patrimonio de recuperar sus antiguos bienes y de incrementar los que le restaban facilitaba las cosas, acelerando al máximo los trámites de concesión de licencias de establecimiento que, por ende, se producian en la Bailia alicantina con cierta profusión. Es por ello que, dentro de este contexto en el que los deseos particulares y reales marchaban por idénticos senderos, se justificarian las sucesivas peticiones y concesiones de bienes realengos descritas a lo largo de este trabajo. 


\section{NOTAS:}

(1) A(rchivo) (Histórico) P(rovincial) de A(licante). Protocolos Notariales de Pedro Rovira, $\mathbf{P} / 1560$.

(2) J. CANGA ARGUELLES, Diccionario de Hacienda. Tomo II. Madrid, 1834. Reimp. Instituto de Estudios Fiscales. Madrid, 1968. Pp. 344-348.

(3) Archivo del Reino de Valencia. Bailia AE, Exp. 168. E igualmente en V. BRANCHAT, Tratado de los derechos y regallas que corresponden al Real Patrimonio en el Reino de Valencia, Valencia MDCCLXXXIV, Tomo I, pp. VIII-XX del Apéndice de documentos.

(4) V. BRANCHAT, Op. cit., Tomo I, pp. 353-363.

(5) V. BRANCHAT en su Op. cit., vol I, pp. 1-49 refiere las sucesivas enajenaciones del Real Patrimonio desde su conquista. El jurista valenciano P. H. TARAÇONA reseña los diversos fueros promulgados para frenar la desmembración patrimonial; para ello vid. Institucions dels Furs i Privilegis del Regne de Valencia, Valencia, 1580. Llibre III, Títol VIII, pp. 300-309 del facsimil editado por Del Cenia al Segura, Valencia, 1976.

(6) "La expulsión de los moriscos fue el principio de la decadencia que en el dia experimenta el Real Patrimonio en sus derechos y regalías particulares. Porque no sólo quedó desde entonces privado de muchas y dilatadas posesiones, cuyo dominio territorial se transfirio a los barones, sino que aún el uso de la regalia de establecer hornos y molinos padeció mucha confusion y desorden". Cfr. en V. BRANCHAT, Op. cit., Tomo I, p. 76.

(7) J. CANGA ARGUELLES. Op. cit., Tomo II, p. 346. 204.

(8) J. M. IBORRA LERMA. Realengo y señorio en el Camp de Morvedre. Sagunto, 1981. P.

(9) C. GARCIA MONERRIS, "Canga Argüelles y el Patrimonio Real de Valencia: 1805-1806m, en Estudis d'Historia Contemporania del Pals Valencià, n. ${ }^{\circ} 1,1979$, pp. 137-163. J. M. IBORRA LERMA, Op. cit., pp. 195-204.

(10) Ibidem, Tomo I, pp. XC.CXXXVI.

(11) V. BRANCHAT, Op. cit., Tomo I, p. CXXVIII.

(12) A. ALBEROLA ROMA, "Análisis y evolución histórica del sistema de riego en la huerta alicantina". Anales de la Univ. de Alicante. Historia Moderna, n. ${ }^{\circ}$ (1981), pp. 117-140.

(13) E. GIMENEZ LOPEZ, Alicante en el siglo XVIII. Economia de una ciudad portuaria en el Antiguo Régimen. Valencia, 1981, p. 87.

(14) A(rchivo) M(unicipal) de A(licante). Cartas escritas, Armario 12, Libro 67. Sin foliar.

(15) Los datos se han elaborado a partir de documentación procedente de los archivos AMA y AHPA, concretamente de la Correspondencia de la ciudad y de los Expedientes de nuevos establecimientos. Los datos que ofrece E. GIMENEZ en su op. cit. pp. 131-133 son ligeramente inferiores a los nuestros debido a que en su momento le fue imposible manejar la segunda documentación aludida al no haber sido abierto aún al público el Archivo Histórico de Alicante.

(16) M. ARDIT LUCAS, Revolución liberal y revùelta campesina, Barcelona, 1977. Pp. 20-33.

(17) AHPA. Protocolos Notariales de Pedro Rovira, P/1560, ff. 31v-38, e igualmente Lista de los enfiteutas de la Bailia, $\mathrm{HB} / 801$.

(18) En el caso de don Julián Colomina se traia a colación «...la antiquisima posesión en que se halla... de aprovecharse de dichas aguas, en la que fue amparado legitimamente en el año $1729 . . . "$.

Respecto a los herederos de Pablo Mallol existía una sentencia de la Real Audiencia por la que se declaraba la pertenencia privativa de u...el dominio, usos y aprovechamiento de las aguas que producian las dos fuentes que están... a principio de dicho barranco...n.

Vid. AHPA. Ibidem, fol. 33v.

(19) Es el caso del establecimiento concedido a José Pastor de una fuentecilla y las aguas 
pluviales que discurrieran por su heredad pagando un canon anual de 5 sueldos. Recibió idéntico trato D. Juan Bautista Puigsever al obtener dos manantiales de agua que nacian en sus tierras de la partida del Porquet. El canon anual, en este caso, ascendia a una Libra. Por último cabe citar el establecimiento concedido al presbítero D. Juan Sanz y Colomina que le permitia disfrutar, satisfaciendo una pensión anual de 5 libras, de todas las aguas que fluyeran por la rambla de la partida del Alabastro. Cifr. en AHPA, Lista de los enfiteutas de la Bailia, HB/801.

(20) AHPA. P/1560, ff. 1-4.

(21) Estas obras se concretaban en la construcción de «...un azud que tenga doscientos palmos de largo, doce de alto y diez de grueso, con doce estribos proporcionados, todo de mamposteria ordinaria......, como también edificar en los galladores de la falda del indicado barranco seis arcos para que tengan desagũe aquellos..... y por encima de la pared y los arcos haya de encaminarse dicha agua mediante una acequia de cuatro palmos de ancho...".

(22) AHPA, P/1560, ff. 32-34v.

(23) AMA, Cabildos, Arm. 0, Lib. 41, ff. 88v y ss.

(24) AHPA. Protocolos Notariales de Pedro Rovira, P/1560, ff. 47v-51v. Vid. Igualmente AMA. Cartas Escritas, Arm. 12, Lib. 66, s. fol.

(25) A. J. CAVANILLES, Observaciones sobre la historia natural, geografia, agricultura... del Reyno de Valencia. Madrid, 1797. Vol. II, p. 248.

(26) A este respecto se pueden consultar los Memoriales elevados a lo largo del siglo XVIII por los terratenientes y vecinos de las partidas de la Albufereta, Condomina y Almaxá. AMA. Cabildos, Arm. 9, Libs. 6, 7, 11 y 42. Un estudio de mayor alcance relativo al problema de las tercianas y a la desecación de la Albufereta aparecerá en el VII Congreso Nacional de Historia de la Medicina celebrado en Alicante en 1983.

(27) F. FIGUERAS PACHECO, El antiguo puerto interior de la Albufereta de Alicante. Alicante, 1955, 52 pp. 